\title{
Feasibility of percutaneous needle aspiration for the treatment of breast abscesses
}

\author{
Karam K. Younis \\ From the Department of Surgery, College of Medicine, University of Mosul. \\ Correspondence: Karam K. Younis. Assistant Professor, Department of Surgery, College of Medicine, University of Mosul, \\ Mosul, Iraq. Email: karam_kamal66@yahoo.com. \\ (Ann Coll Med Mosul 2013; 39 (1): 65-69). \\ Received: 10 $0^{\text {th }}$ Jun. 2012; Accepted: $18^{\text {th }}$ Nov. 2012.
}

\begin{abstract}
Objective: To assess the feasibility and effectiveness of percutaneous needle aspiration under local anesthesia for the treatment of acute breast abscesses in the outpatient breast clinic.

Design: A retrospective study of forty three female patients with acute breast abscesses.

Setting: Breast clinic in Al Jamhoory teaching hospital in Mosul between February 2004 to February 2007.

Methods: Forty three patients with acute breast abscesses were studied. Special enquiries were made regarding lactation, symptomatology and sites of abscesses. All patients had preliminary breast ultrasound (U/S) examination. In the breast clinic, percutaneous needle aspiration of pus under local anesthesia was done followed by systemic antibiotic therapy. Repeated aspiration was carried out later when deemed necessary and follow up by (U/S) was conducted.

Results: Forty three patients aged between 16-75 years (mean 37 years) having a provisional diagnosis of acute breast abscesses. All patients presented with a palpable tender mass, of which 4 patients had retroareolar abscesses. All patients had (U/S) of breast. Five patients were found on breast $\mathrm{U} / \mathrm{S}$ to have inflammation without evidence of focal pus and they only required antibiotics. Four patients refused aspiration and underwent primary incision and drainage under general anesthesia (GA), while in two patients the abscesses were pointing and opened spontaneously before intervention, and they settled with wound toilet and antibiotics alone.

The remaining thirty two patients had their abscesses aspirated, and the treatment was successful in twenty nine patients $(91 \%)$ with no complications or recurrence. The treatment failed in three patients who required subsequent incision and drainage.

Conclusions: Percutaneous needle aspiration of acute small unilocular breast abscesses after prior breast (U/S) followed by systemic broad spectrum antibiotics is successful, when the abscesses are completely drained. The use of this modality of the treatment has still not found wide application in our locality. This study is an attempt to recommend its use wherever facilities exist for its feasibility, low cost, no interruption with lactation and better cosmesis, though incision and drainage still may be necessary for definitive treatment for large or multilocular abscesses.
\end{abstract}

Keywords: Breast, abscess, aspiration.

\section{جدوى استعمال السحب بالإبرة لمعالجة خراجات الثي}

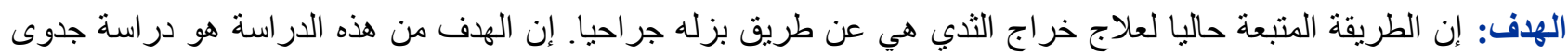

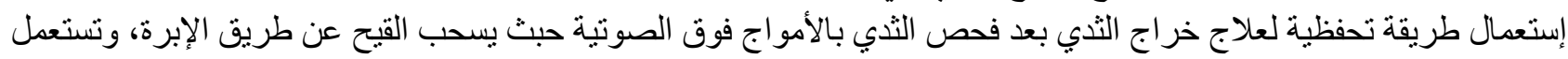

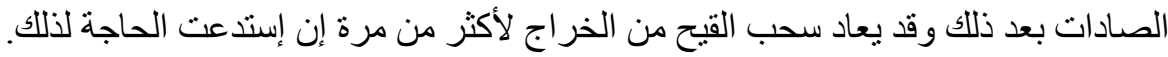

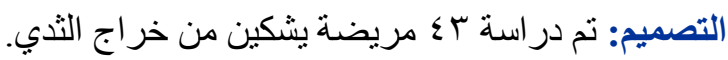


المكان والزمان: تمت الدر اسة في عيادة أمر اض الثذي في المستشفى الجمهوري التعليمي بالموصل في الفترة بين شباط ؟ ...

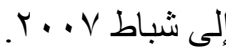

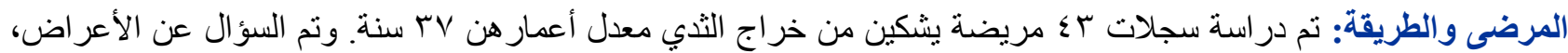

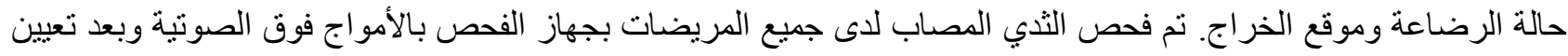

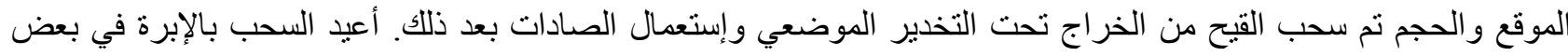

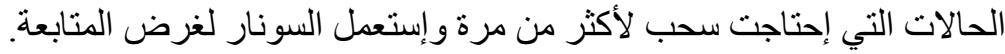

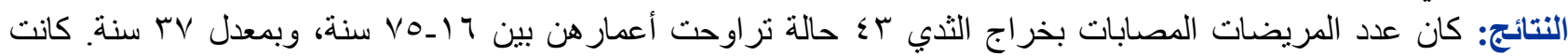

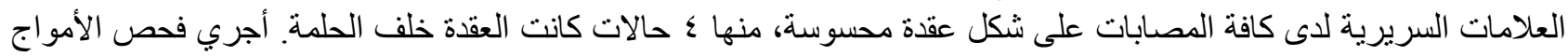

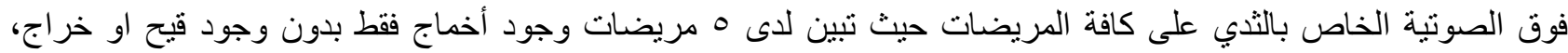

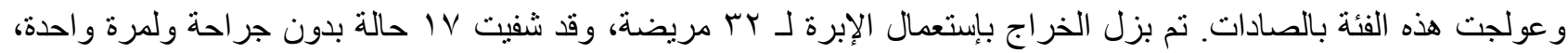

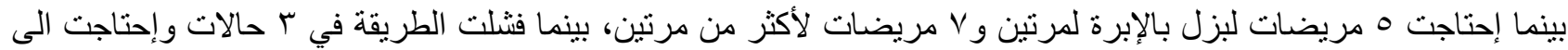

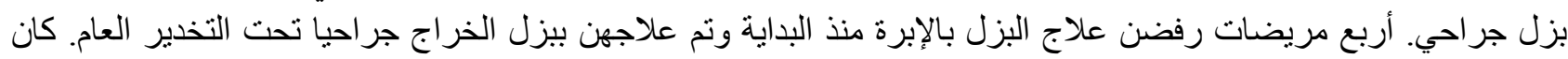

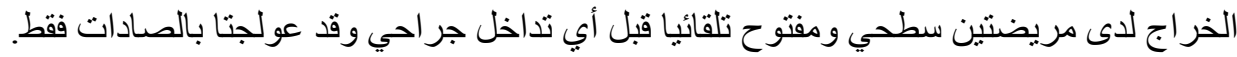

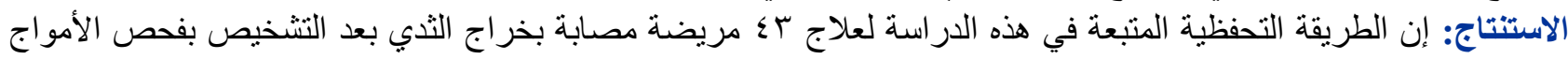

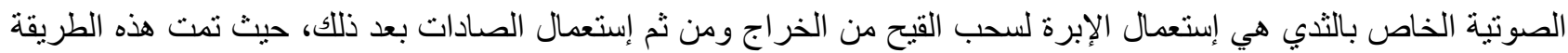

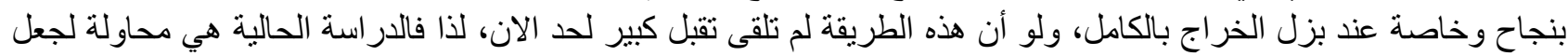

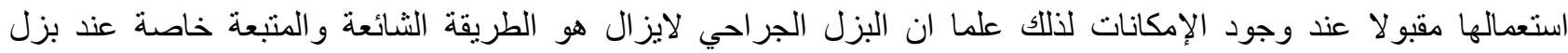
الخر اجات الكبيرة او المزمنة. الخئ.

$\mathrm{T}$ he traditional surgical treatment of breast abscess consists of an incision over the point of maximal tenderness (or fluctuation) and digital disruption of abscess septa. ${ }^{(1)}$. The abscess cavity is left open and packed with gauze, with subsequent dressing changes for up to 6 weeks during wound granulation ${ }^{(2)}$. This strategy is often done under general anesthesia especially in children. The incision is often disappointing cosmetically owing to scar formation and interference with lactation ${ }^{(3)}$. Battle and Baily quoted by Uriburu in 1923 first suggested that breast abscesses could be successfully treated by percutaneous aspiration of pus and irrigation of the cavity with Dakin's solution ${ }^{(4,5)}$. In 1946, Flory was the first to consider the possibility of daily aspiration of small abscesses and direct injection of penicillin soon after the drug became available at the end of World War $I^{(6)}$. Regarding assessment, ultrasonography $(\mathrm{U} / \mathrm{S})$ has been shown to be useful in depicting abscesses in patients with mastitis ${ }^{(7,8)}$. Later on it was used to guide and facilitate complete drainage of breast abscesses compared with blind aspiration as it enabled visualization of multiple abscess loculations ${ }^{(9)}$. Subsequently, imaging guided percutaneous aspiration of purulent breast collection was increasingly popular in the 1980s, ${ }^{(10)}$ as Karstrup et al in 1990 reported successful percutaneous US guided aspiration of breast abscesses $^{(11)}$.

The purpose of the current study is to assess whether needle aspiration with the aid of US and subsequent systemic antibiotics is a feasible alternative treatment option for breast abscesses.

\section{PATIENTS AND METHODS}

Fourty three female patients with mastitis and clinical suspicion of acute breast abscesses attended the Breast Clinic at Al Jamhoory Teaching Hospital for the period from February 2004 to February 2007. The data gathered included age, lactation and breast symptoms as (discharge, red skin, fever, tender lumps). The site of the abscess in relation to the breast was recorded. Special note was made on the use of preliminary diagnostic breast $(\mathrm{U} / \mathrm{S})$ to demonstrate the presence or absence of pus, and to guide further treatment by aspiration. The U/S examination was performed by radiologists with 7$13 \mathrm{MHZ}$ linear array transducer. The long axis diameter of the abscesses was checked. The aspiration procedure was performed on an outpatient basis in the Breast Clinic by the same 
surgeon using $14 \mathrm{G}$ sterile needle under local anesthesia at puncture site $(2 \mathrm{ml}$ of $2 \%$ plain lignocaine anesthetic solution). The aspiration was not attempted on 5 patients who had U/S features of acute mastitis with no pus collection. Aspirated pus material was sent for culture and sensitivity. Aspiration was followed by irrigation of cavity thoroughly with about $50 \mathrm{ml}$ of sterile $0.9 \%$ isotonic saline solution until aspirate returned clear. Post procedural U/S images were obtained to evaluate any residual fluid collections. Parenteral cefotaxime (1 gm) bid was prescribed on discharge from clinic. Further aspiration was done when necessary in the next 2- 3 days. Patients were scheduled for follow up one week later by $\mathrm{U} / \mathrm{S}$ for any residual pus collection. Followed up was stopped when clinical evidence of inflammation or residual collection no longer seen on sonography. Lactating patients were encouraged to continue doing so. Our management algorithm is demonstrated in (Figure 1).

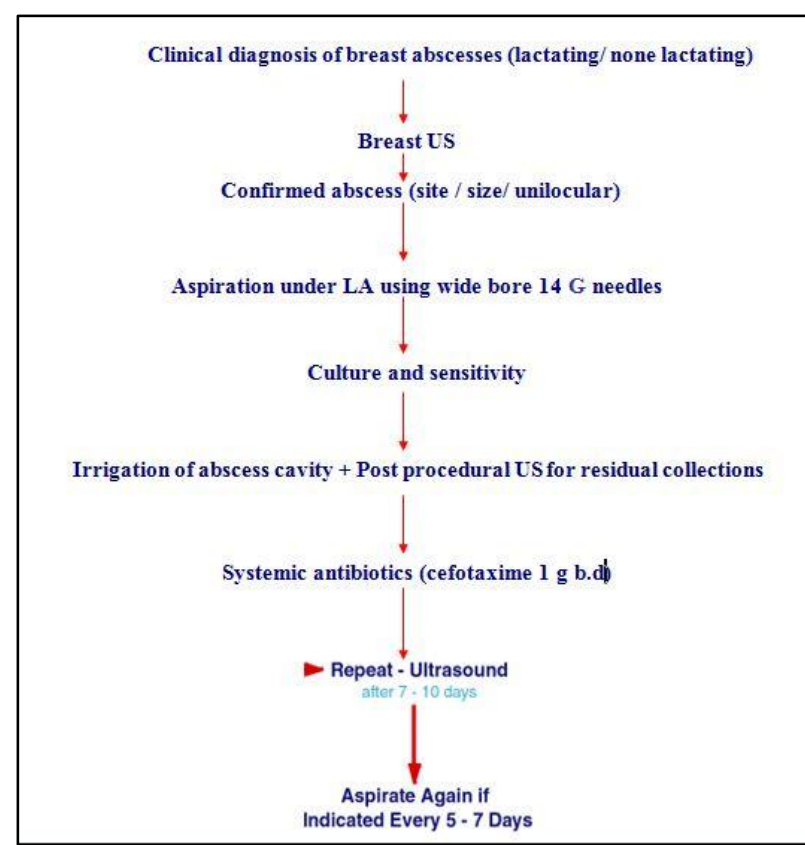

Figure 1. Management algorithm for treatment of 43 patients with breast abscess.

\section{RESULTS}

A total of 43 female patients with mastitis and clinical suspicion of acute breast abscesses were seen. The mean age was 37 years; their age range was (16-75) years. Thirty sex patients (84\%) were lactating and seven patients (16\%) were none lactating.
Clinically, the inflammatory abscesses were situated peripherally in 39 patients $(91 \%)$ while in four patients $(9 \%)$ the abscesses were located centrally in the retro-areolar space.

All patients presented with complaints of acute, firm, tender, palpable mass or masses in the breast. Seventeen patients (40\%) had redness of the overlying skin, and one reported having a thick, discharge from the nipple as in Table 1.

Ultrasonographic examination of the breast demonstrated an evidence of focal hypoechoic unilocular type of breast collection in (38) patients, (Figure 2). The remaining five patients had (U/S) features of acute mastitis and were excluded from the study. The $(\mathrm{U} / \mathrm{S})$ long axis diameter of the abscesses ranged from 0.8 to $7.0 \mathrm{~cm}$ (average 2.8 $\mathrm{cm}$ ) as measured by the calipers on the sonogram. In two patients, the abscesses were spontaneously discharging through a thinned out overlying skin and those were excluded from aspiration and were treated by a mini- incision with daily change of dressing. Four patients refused aspiration and elected surgical drainage under GA. Of the remaining (32) patients who completed the treatment, there was a difference in abscess resolution after aspiration between patients on follow up (U/S). Seventeen patients had complete resolution (no focal collection) after single aspiration, five patients required two aspirations, (Figure 3), and seven patients required more than two aspirations for cure requiring no further intervention. In only three patients with abscesses larger than $3 \mathrm{~cm}$ in maximum dimension, the treatment failed, where symptoms not resolved after 3 days with further pus collection despite aspiration and cefotaxime that necessitated surgical drainage as in Table 2.

Pus from the abscesses following aspiration and culture grew staphylococcus aureus as the commonest pathogen on aerobic culture, whereas other microorganisms were found in minority of cases (Table 3).

Table 1. Clinical presentations of patients.

\begin{tabular}{|l|c|c|}
\hline \multicolumn{1}{|c|}{ Symptoms } & No. & $\%$ \\
\hline Discharge & 1 & 2 \\
\hline Tender Lump & 43 & 100 \\
\hline Fever & 12 & 28 \\
\hline Red skin & 17 & 40 \\
\hline
\end{tabular}


No complications or recurrence were observed in the 29 patients (91\%) successfully treated with needle aspiration and antibiotics on repeat (U/S) during the follow up visits.

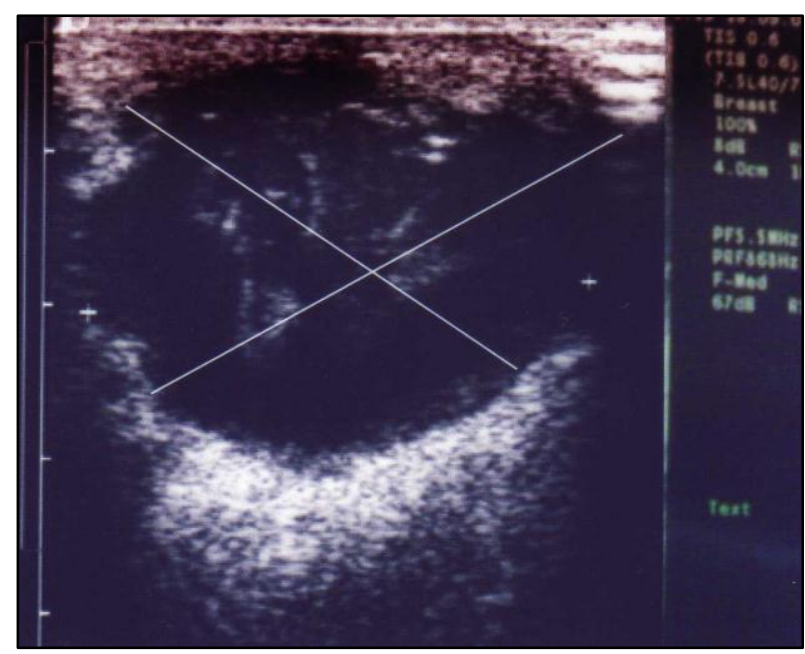

Figure 2. Sonogram of breast abscess with low internal echo pattern before initial aspiration of $20 \mathrm{~mL}$ of pus.

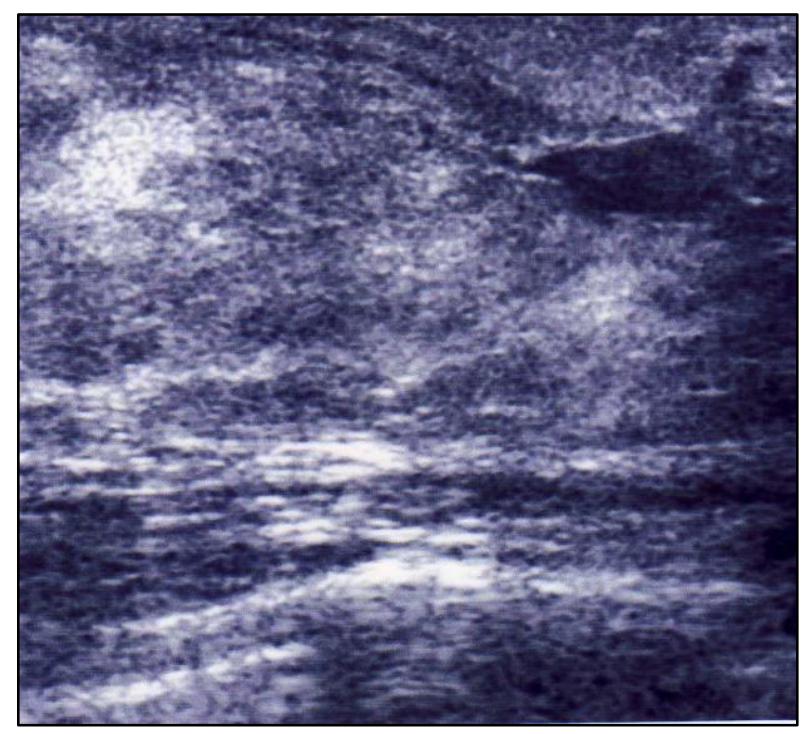

Figure 3. Breast abscess in the same previous patient after two needle aspirations. Complete resolution of abscess and internal echoes has cleared.

Table 2. Treatment of patients by aspiration.

\begin{tabular}{|l|c|c|}
\hline \multicolumn{1}{|c|}{ Profile of treatment } & No. & $\%$ \\
\hline One aspiration & 17 & 53 \\
\hline Two aspirations & 5 & 16 \\
\hline More than two aspirations & 7 & 22 \\
\hline Treatment failure & 3 & 9 \\
\hline TOTAL & 32 & $100 \%$ \\
\hline
\end{tabular}

Table 3. Isolation of bacteria from breast abscesses.

\begin{tabular}{|l|c|c|}
\hline \multicolumn{1}{|c|}{ Bacterial growth } & Lactating & $\begin{array}{c}\text { Non - } \\
\text { lactating }\end{array}$ \\
\hline Staphylococcus aureus & 7 & 14 \\
\hline $\begin{array}{l}\text { Staphylococcus aureus and } \\
\text { streptococcus haemolyticus }\end{array}$ & --- & 3 \\
\hline S. epidermidis & --- & 5 \\
\hline No growth & --- & 3 \\
\hline
\end{tabular}

\section{DISCUSSION}

In the current study, patient's age range has some similarity with the results of Dixon JM who demonstrated that breast abscesses most commonly affect women aged 18 to $50^{(2)}$. Although breast abscess generally has been associated with mastitis and breast feeding, the results of our study and others ${ }^{(12)}$ indicate that abscess is not uncommon in non-lactating women mostly due to periductal mastitis. In our series, the frequency of lactational abscesses was (16\%). This is in agreement with Crowe et al study who reported a $5 \%$ incidence of lactating abscesses in 21 patients ${ }^{(8)}$ and so for the incidence of $8.5 \%$ reported by Scholefield et al in 72 patients ${ }^{(13)}$. In this study; the finding of peripherally locating abscesses more than centrally locating contradicts with Dixon JM results who reported that peripheral breast abscesses are less common than periareolar one ${ }^{(2)}$. In the procedure of aspiration; some patients experienced discomfort during aspiration. This feeling could have been resolved if prior application of local anesthetic cream at puncture site for one hour was done to make aspiration acceptable ${ }^{(10)}$ but unfortunately it was not available in our breast clinic. The results of this study showed that most of the abscesses (67\%) can be treated with aspiration and antibiotic therapy if the abscess cavity is completely or almost completely drained. The findings of residual collection on follow up (U/S) in the patients studied emphasize the need for follow up imaging in the next referral to the clinic. O'Hara et al reported an $85 \%$ cure rate of 22 abscesses, some of them aspirated without sonographic guidance ${ }^{(12)}$. Schwarz and Shrestha also reported aspiration without sonographic guidance plus oral antibiotics in 33 abscesses, with a resultant cure rate of $82 \%$. Their success rate was correlated with a mean volume of pus at the first aspirate of $4.6 \mathrm{ml}$, compared with failures in abscesses with a mean volume of 21.5 $\mathrm{ml}$. In larger abscesses, aspiration was not always 
successful in abscess drainage. ${ }^{(10)}$ Hook and lkeda reported a $54 \%$ cure rate of 13 breast abscesses treated by aspiration and irrigation while they reported a failure in patients in whom the abscess of more than $3 \mathrm{~cm}$ in diameter ${ }^{(9)}$, a finding similar to the present study where 3 of our patients with larger abscesses had failure of treatment. Dixon et al, however, reported successful aspiration of six lactating abscesses with a mean volume of $26 \mathrm{ml}$ (14) while R. Eryilmaz stressesed that the risk factors for failure of needle aspiration for breast abscesses were abscesses larger than $5 \mathrm{~cm}$ in diameter, unusually large volume of aspirated pus, and delay in treatment ${ }^{(15)}$. In their retrospective study that included 39 patients, Juan $D$ et al showed that percutaneous drainage procedures in breast abscesses are a safe and effective alternative to incision and drainage (16). After reviewing 63 papers; Thirumalaikkumar et al concluded that the smaller the abscesses the better is the outcome and the lower is the recurrence rate following aspiration ${ }^{(17)}$. According to Strauss $A$ et al and Imperale A, surgery or other decompression methods were required for definitive treatment in chronic or complicated abscesses ${ }^{(18,19)}$. The range of bacteria isolated from abscesses in the current study confirms the need of using broad spectrum antimicrobial following aspiration (as cefotaxime in this study) rather than the traditional antistaphylococcal antibiotics as other microorganisms were recovered in the culture of abscesses studied and could be a cause of failure treatment in these patients.

In conclusion; the results of our study showed that percutaneous needle drainage of breast abscesses after preliminary assessment by breast $(\mathrm{U} / \mathrm{S})$ to confirm the diagnosis and guide the need and adequacy of aspiration is well tolerated, feasible primary and definitive treatment for most acute unilocular small breast abscesses, if complete or near complete drainage is achieved. We have seen a success rate of $(91 \%)$ in patients completing treatment. Needle aspiration may be more effective when combined with systemic broad- spectrum antibiotics. Formal surgical drainage may be best reserved for few patients after failure of aspiration method. No complications or recurrence were encountered with this minimally invasive technique.

\section{REFERENCES}

1. Preece PE. The breast. In: Cuschieri A, Giles GR, Moosa AR, eds. Essential surgical practice. Bristol, England: Wright, 1982.p.811-831.

2. Dixon JM. Outpatient treatment of non-lactational breast abscesses. Br J Surg 1992; 79:56-5.

3. Watt-Boolsen S, Rassmussen NR, Bilchert-Toft M. Primary periareolar abscess in the nonlactating breast: risk of recurrence. Am J Surg 1987; 153:571-573.

4. Battle RJ, Bailey GN. The treatment of acute intramammary abscess by incision and aspiration. $\mathrm{Br} \mathrm{J}$ Surg1923; 10:436 -441.

5. Uriburu JV, Uriburu JL, Mosto D, et al. Infecciones de la mama: mastitis. In: Uriburu JV, ed. La mama, vol.2. Buenos Aires: Libreros Lopez; 1966.p.581-582.

6. Florey ME, Macrine JS, Rigby MAM. Treatment of breast abscesses with penicillin. Br Med J1946; 2:896 901.

7. Ozseker B, Ozcan AU, Rasa K, Cizmeli OM. Treatment of breast abscesses with ultrasound-guided aspiration and irrigation in the emergency setting. Emergency Radiology 2008;15:105-108.

8. Crowe DJ, Helvie MA, Wilson TE. Breast infection: mammographic and sonographic findings with clinical correlation. Invest Radiol 1995; 30:582-587.

9. Hook GW, Ikeda DM. Treatment of breast abscesses with US-guided percutaneous needle drainage without indwelling catheter placement. Radiology 1999; 213:57982.

10. Schwarz RJ and Shrestha R. Needle aspiration of breast abscesses. Am J Surg 2001; 182:117-119.

11. Karstrup S, Nolsoe C, Brabrand $K$, Nielsen KR. Ultrasonically guided percutaneous drainage of breast abscesses. Acta Radiol 1990; 31:157- 159.

12. O'Hara RJ, Dexter SPL, Fox JN. Conservative management of infective mastitis and breast abscesses after ultrasonographic assessment. $\mathrm{Br} \mathrm{J}$ Surg 1996; 83:1413-1414.

13. Scholefield JH, Duncan JL, Rogers K. Review of hospital experience of breast abscesses. $\mathrm{Br} \mathrm{J}$ Surg 1987; 74:469-470.

14. Dixon JM. Repeated aspiration of breast abscesses in lactating women. BMJ 1988; 297:1517-1518.

15. Eryilmaz M, Sahim M, Hakan TM, Daldal E. Management of lactational breast abscesses. The Breast 2003;14:375 - 379.

16. Berna-Serna JD, Madrigal M, Berna-Serna JD. Percutaneous management of breast abscesses. An experience of 39 cases. Ultrasound in Medicine \& Biology 2004; 30:1- 6 .

17. Thirumalaikumar $S$, Kommu S. Aspiration of breast abscesses Emerg Med J 2004;21:333-334.

18. Strauss A, Middendorf K, Muller-Egloff S, Heer M, Untch M, Bauerfeind I. Sonographically guided percutaneous needle aspiration of breast abscesses - a minimal-invasive alternative to surgical incision. Ultraschall Med 2003; 24(6):393 -7.

19. Imperale A, Zandrino $F$, Calabrese $M$, et al. Abscesses of the breast. US-guided serial percutaneous aspiration and local antibiotic therapy after unsuccessful systemic antibiotics. Acta Radiol 2001; 42:161. 